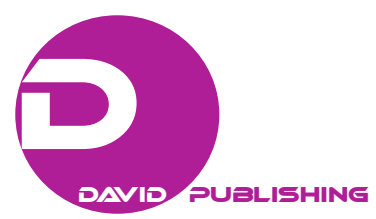

\title{
Innovation Process in Medium-sized Italian Fashion Firms: A Longitudinal Case Analysis
}

\author{
Maria Rosaria Marcone \\ Marche Polytechnic University, Ancona, Italy
}

\begin{abstract}
Attention to technological innovation is focused on the belief that aesthetic innovation can be either facilitated or inhibited within this open innovation setting where limited protection and dynamic knowledge flows occurring across organizations. The clothing industry in Italy was chosen as a target context, because many innovative pioneering medium sized enterprises (MSEs) were operating in the industry and we decided to adopt a research methodology based on the use of a qualitative analysis of business cases. The data were collected in three regions of Italy: Emilia Romagna, Marche, Umbria visiting investigated companies over six years (2010-2017). From a part of the necessity of deep organizational engagement with integrated stakeholders, the results imply that firms choose a multiple stakeholders integration strategy with particular attention to supply side relationships in the sense that they vary in their openness towards up-stream supply chain.
\end{abstract}

Keywords: sustainable supply chain, open innovation, manufacturing system

\section{Introduction}

The goal is to investigate what new dynamic capabilities are being developed and enriched in innovative fashion companies. Starting from the Resource Based View (RBV), we try to typify the form of openness innovation put in place by companies that are related to companies in the same supply chain preferring contacts, especially from the supply side (with suppliers), or with operators belonging to supply chains that are profoundly different and far from traditional fashion supply chains. What emerges is how innovation within the supply chain impacts on strategic decision-making processes and on the managerial performance of companies in relation to each other. Scholars are then called to interpret open innovation using the conceptual categories of relational.

It is also a matter of analyzing which are the inspiring principles of $R \& D$ activities, that is if the research efforts (entity and type of resources employed, design of research oriented processes, innovative intership, etc.) are pushed by the economic actors of the supply chain (push technology innovation) or if they are pulled by down-stream actors belonging to the same supply chain or to other supply chains or finally if they are requested by customers (retailers or final clients) (pull technology innovation).

This paper is structured as follow. The first part presents a structured analysis of the theoretical framework (see Figure 1); subsequently the methodology used is presented; finally, the first results of a research still underway and the concluding observations are exposed.

Maria Rosaria Marcone, full professor on Business Economics, Department of Management, Marche Polytechnic University, Ancona, Italy.

Correspondence concerning this article should be addressed to Maria Rosaria Marcone, Department of Management, Marche Polytechnic University, P.le Martelli, n. 8, Ancona 60121, Italy. 


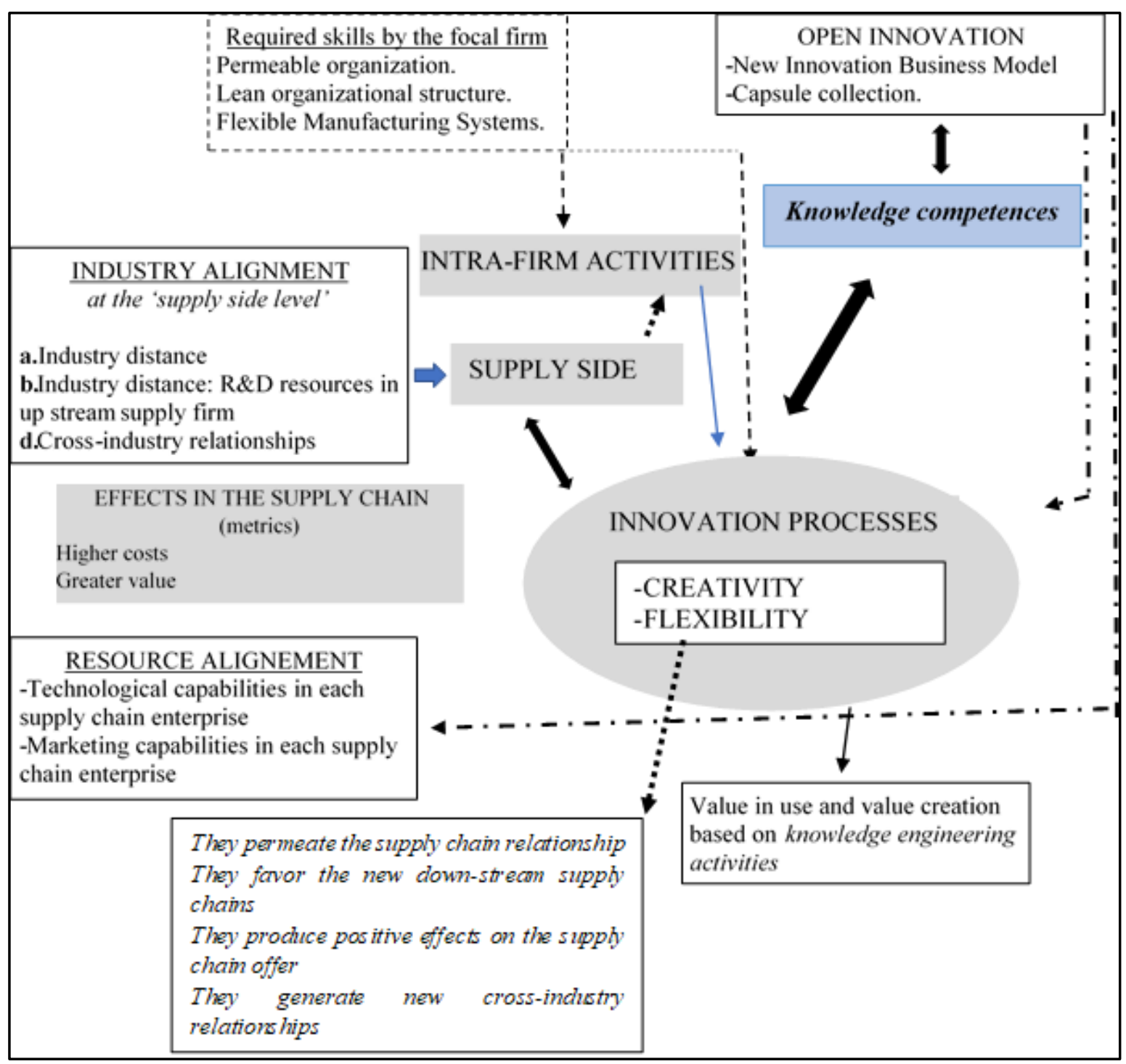

Figure 1. Innovative processes in knitwear supply chain. Source: our elaboration.

\section{Theoretical Framework}

Using the theoretical framework of the RBV we try to interpret the almost natural propensity of openness innovativeness of companies that are related to companies in the same supply chain, especially from the supply side, or belonging to deeply different supply chains.

Open innovation is a very complex phenomenon that leads us to review the impact that innovation has on the economic and non-economic actors involved in the various innovative phenomena.

It is increasingly important for entrepreneurs, managers, financiers and institutional economic bodies to understand the effectiveness of the "widespread innovative phenomena", by analyzing the outcomes of joint inventing and the competitive performance acquired by the companies involved. Instead, an understanding of value creation and value capture is paramount for advancing our understanding of sustained open-innovation activities. Open innovation requires collaboration among distributed but interdependent actors who rely on each other's capabilities for value creation and capture (Chesbrough, Lettl, \& Ritter, 2018). 
According to the resource based view, network scholars point out that academics interest in the prerequisites of business, or strategic networks successful exploitation is much more recent. From a resource based perspective firms differ in their capability to shape and exploit networks, to extent that their capability to leverage networks has been identified as distinctive.

If firms seek increased market, innovation and financial performance, they need to develop network specific capabilities. One such critical capability refers to management skills and competencies in developing valid views of networks and their potential evolution, a condition to perceive the opportunities embedded in networks.

Recent empirical studies re-systematize the conceptualization of network pictures by testing the dimensions of this concept and adopting a dynamic view, focused on the processes through which networks are understood and strategy enacted within them (Czakon \& Kawa, 2018). This is particularly useful, in order to avoid the appearance of myopia networks in literature and in managerial practices.

Similar to relational based view the network perspective sees markets as business network, where business units or firms are represented by nodes, and long-term complex interactions between them are represented by links (Håkansson \& Ford, 2002).

H1: The propensity of multiple actors to design new supply chains is assumed in which companies are linked by sustainable relationships.

Previous research has examined open innovation and its related interactive mechanism then contributed to the understanding of how generate outcomes in innovative relationships (West \& Bogers, 2014; Spender, Corvello, Grimaldi, \& Rippa, 2017). The openness innovative phenomena have received a significant amount of attention from scholars and practitioners over the past decade, but its definition derives from a long stream of economics literature on the spillovers that can arise from R\&D activities (Chesbrough et al., 2018). Moreover, evidence regarding the role of actors remains fragmented. For instance, the relationship between innovation creator actors (firms, start up, team work) and innovation seekers (founders, business angels, ect.) is understood. The most analyzed are the contexts of R\&D collaborations and technology alliances (Eikhof \& Haunschild, 2007; Faems, de Visser, Andries, \& van Looy, 2010; Lin, 2018). Thus, research attention to diverse supply chain should be considered.

Over recent years many studies have pointed to creativity as a principal driver of innovation and profitability of firms. According to the most modern literature, innovation process starts from a creative idea that must overcome some of the obstacles such as technology challenges and competitive pressures (Anderson, Jeanrenaud, Bessant, Denyer, \& Overy, 2014). Hence, no innovation is possible without the creative processes as the latter is often an initial invention or deep insight in some of several stages of innovation (Yusuf, 2009). From there it follows that creativity is a multi-dimensional concept that encompasses team workers, organizational, supply chain relationships and multi-level perspective.

Firms more and more develop processes to seek out and transfer external knowledge into their own innovation activities. In this sense, $R \& D$ activities are inspired by the industrialization of push technology innovation.

X2: The technological innovations of fashion firms are also push type.

The company's deep organizational engagement with stakeholders is crucial for achieving high sustainability performance of innovation. This in the sense that in companies of not large size, where entrepreneurship is strong and where an important decision-making role is attributed to the department heads 
by virtue of their embedded knowledge, it emerges that the organizational structures are completely involved in the growth processes of sustainable innovative productive systems.

The following is therefore hypothesized.

X3: Multiple and shared strategic commitment for high sustainability performance of innovation is required.

\section{Methodology}

Owing the study's exploratory nature, we decided to adopt a research methodology based on the use of a qualitative analysis of business cases (Yin, 2003). Case studies have several advantages; first, they allow one to understand the relationships between a phenomenon and its context and enable scholars to match different data that could enhance a research object's analysis (Dubois \& Gadde, 2002). Second, as Stake (1995) notes, case study methods allow one to investigate and to interpret new innovative phenomena both in managerial and in strategic sense, in real time.

The clothing industry in Italy was chosen as a target context, because many innovative pioneering MSEs were operating in the industry.

This study initiated by selecting appropriate business operators (department heads, workers to computerized weaving machines) and area managers who are demanded representative for this research activity. A preliminary round of interviews with designers (or stylists) and entrepreneurs, the founders of the innovative fashion business models, was conducted. Preliminary set of data was collected during the Pitti week in Florence and during the fashion week in Milan. These are industry events, among the most prestigious in the world, which take place at certain times each year and in which well-known companies from the Italian fashion and independent high-end fashion designer business gathering in Florence and Milan showcased their aesthetic (rational or kinesthetic) product innovations for the upcoming season, with businesses ranging from established fashion firms to emerging start-ups. Interviewees' names were kept anonymous due to pre-interview agreements of anonymity.

The second round of data collection was conducted. There were 65 semi-structured interviews involving economic operators at various stages of the supply chain, the consulting organizations, representatives of trade associations, representatives of technical schools and universities.

The data were collected in three regions of Italy: Emilia Romagna, Marche, Umbria visiting investigated companies over six years (2010-2017).

\section{Knitwear Supply Chain: Innovative Relationships in the Openness Supply Chain}

As is known, according to the relational based view, firms utilize relationships for competitive advantage by accessing, integrating, and leveraging external resources. In the theoretical contributions it emerges how the relationships are relevant across a myriad of relationship forms, including alliances, joint ventures, supply agreements, cross-sector partnerships, networks, and consortia. Specifically, in this contribution we consider the effects of power-based behaviors in innovative supply chain relationships involving interdependent supply chains on relational outcomes. Firms' behaviors toward their business partners vary in the direction, extant and approach that the commitment of supply chain partners in innovation projects is exerted.

Networks are structures that decode and convert information in operational sources, innovation inputs and market opportunities, provide a competitive advantage to some actors over others, and offer opportunities otherwise unavailable. 
First, the strength of the relationship between bridging structural holes and firm innovation is likely to vary depending on whether the heterogeneous knowledge comes from firms that are different from or similar to a focal firm.

To enhance their innovation, firms need not only market knowledge, such as the knowledge about market trends, customer needs, and competition, but also technological knowledge, such as the knowledge about methods, processes, applications as well as product parts and the linkages between the parts. Thus, it is expected that the market and technological distances between a focal firm and its network partners are likely to impact how the focal firm might assess the potential value of the type of knowledge provided by bridging structural holes in its ego network.

Because incremental and breakthrough innovation involves different types of resources and activities (e.g., Colombo, von Krogh, Rossi-Lamastra, \& Stephan, 2017; Qi Dong, McCarthy, \& Schoenmakers, 2017), the heterogonous knowledge that a focal firm might be exposed to from its network partners is likely to influence its innovation differently.

By virtue of the design skills, the knitwear company is the stage of the knitwear supply chain that "controls-governs" the level of flexibility offered to end consumers and governs the type and extent of flexibility that suppliers are called to provide. Knitwear companies offer the level of flexibility that, while exceeding that of their final customers, maximizes the value that the market recognizes to the flexibility of the entire supply chain.

Knitwear firms develop processes that seek out and transfer external knowledge into their own productive innovation activities. They are also available to identify new ones with the same supply chain partners co-creative innovative processes to move unutilized internal knowledge to other organizations in the surrounding environment. You want to put the focus on the wide distribution of useful knowledge, such that no single research institutions or individual firms have a monopoly on useful knowledge. This, together with environmental uncertainty and the complexities of innovation, requires more permeable organizational boundaries that enable combinations of innovative resources (in R\&D, manufacturing and marketing areas) beyond and individual actor's resource endowment.

Push technological innovation micro segments the sector and redefines the supply structure at least for the following factors: number and type of supply chain stages, technological heritage of supply chain operators, degree of firm's vertical integration.

Over the years, many scholars have attempted to draw a distinction between creativity and innovation. A common starting point in such efforts is the depiction of innovation as sequential process. In this process creativity enters as initial stage of intra-individual cognitive and inter-individual social efforts that result in a generation of novel and useful ideas (Stojic, Hashi, \& Olric, 2018). In reality, in the investigated sector it is noted that creativity is included in all the steps of the innovative processes that permeate the entire supply chain and also that this creativity is inherent in all the innovative processes that follow each other continuously: just think about the multiple designs fashion collections.

The study investigated the positive evaluation of the outputs of innovation, the impact that innovative relationships between producers of knitwear and suppliers have on the flexibility offered by up-stream knitwear supply chain. Most studies have focused exclusively on the benefits derived from additional flexibility enjoyed by the knitwear producer firms neglecting the contribution that the suppliers can provide for the benefit of the operators belonging to the various stages of the supply chain up to the stage of the final customer (Malhotra \& 
Mackelprang, 2012; Mandal, 2015). To gain a better understanding of the producer-supplier flexibility offering, in this research they are analyzed relationship-specific aspects such as relationship age, shared business volume, and others specific factors at the micro-level analysis such as founders, dynamism and complexity of innovative projects.

In the current study we recognize the cost required to provide additional flexibility (Gligor, 2018). As far as costs are concerned, they are determined by the fact that the innovative processes that presuppose the involvement of suppliers generate innovative outputs that are higher than those required by the supply chain step down streams (industrial-buyers, customers). If we then consider the innovative processes linked to open innovation, which, as is known, generate a great possibility of use in the industrial sense of innovative creative processes, the incomplete usability of innovative principles generates the sunk costs of innovative supply chain processes that in no way can they be recovered.

It emerges how the organizational structures are completely involved in the strategic decision-making process that promotes the growth of sustainable innovative processes. Think of the department heads by virtue of their embedded knowledge: they intervene almost automatically, whenever there is a need, in the application of sustainable innovations, concerning the production systems, the information procedures, the materials to be used, etc. They are able to interact with suppliers of innovative materials as well as with suppliers of machinery.

We therefore find that the best innovative performances of sustainable companies are the result of interships between middle management organizational figures in the operations area and how these interactions profitably increase the relational skills of supply chain actors, especially in the cases investigated in the empirical research with supply side actors.

It is very positive that workers in the operations activity are actively exchanging ideas with other disciplines to enhance learning and create knowledge. More precisely, knowledge co-created and shared with non-usual suppliers belonging to other supply chains help knitwear innovative firms to develop new knowledge, and increase in legitimacy, all of which enable it to take off and grow. Because in some studies it is claimed that the relative importance of knowledge from outside an industry's boundaries decreases as the industry matures (Agarwal \& Hoetker, 2007; Linderman \& Chandrasekaran, 2010; Meredith \& Pilkington, 2018), the research findings make it possible to exclude fashion knitwear from the mature sectors of Made in Italy.

The innovative phenomena encountered produce not so much value through the collaborative exchange process but also by the participant's ability to capture the value of other innovative actor's value creation effort in cross supply chain innovative processes.

\section{Findings}

The tension between value creation and value capture is considerably attenuated by the innovative openness phenomena. For example, value creation in open innovation requires firms to be open in order to leverage the knowledge of diverse contributors, while value capture necessitates a tighter, more protective process (paradox of openness) (Laursen \& Salter, 2014). This tension is lost in manufactured-based enterprises that are able to industrialize new knowledge in their production systems. Knowing how to process generates the growth of embedded knowledge: this favors the appropriation of the value of "protective practices".

We believe this research to bring forth a number of theoretical contributions. 
This analysis inductively generated propositions that emphasize the important role played by suppliers towards social sustainability requirements and the reciprocity of the letter's responses to them.

The findings have important managerial implications considering that the innovative supply chain processes in which a leading role is assumed by companies operating in so-called traditional manufacturing sectors generate an increase in flexibility of the entire supply chain. The findings indicate that from a flexibility perspective, knitwear firms perform best when suppliers and buyers exceed their expectations.

This also explains why Italian yarn producers can direct their resources to the innovation offer both in the processed materials and in the production processes adopted to their industrial-buyers and improve their ability to compete at world level. Our findings reveal that the impact of buyer-supplier fit on supply chain performance increases when firms operate in dynamic environments.

Integrating non-value chain stakeholders, such as unusual lenders is useful particularly if the firms are open to untypical idea of product's innovation and are prepared to integrate these so-called secondary stakeholders in early phases of the innovation process. These lenders together with sustainability think-tanks and social enterprises, secondary stakeholders they may not be obvious partners for innovative medium sized firms.

Without previous experience of collaboration, therefore, it may require significant effort to understand the knowledge gaps, to recognize suitable secondary stakeholders, and to create trusting relationships with stakeholders.

In practice, the success of innovative processes requires motivation to innovate and skills in innovation management as well as availability of relevant financial, human, productive, creative resources that can aid innovation.

The focus of the study on Italian fashion luxury knitwear companies has allowed us to develop innovative and creative processes as analogous sequences: innovation process in this framework, with the decision to innovate and advances through stages of investment in innovations, implementation and commercialization in various supply chains also strongly diversified among themselves.

\section{References}

Adams, R., Jeanrenaud, S., Bessant, J., Denyer D., \& Overy P. (2016). Sustainability-oriented innovation: A systematic review: Sustainability-oriented innovation. International Journal of Management Reviews, 18(2), 180-205.

Agarwal, R., \& Hoetker, G. (2007). A Faustian bargain? The growth of management and its relationship with related disciplines. Academy of Management Journal, 50(6), 1304-1322.

Anderson, N., Potocnik, K., \& Zhou, J. (2014). Innovation and creativity in organizations: A state-of-the-science review and prospective commentary. Journal of Management, 40(5), 1297-1333.

Boons, F., \& Lüdeke-Freund, F. (2013). Business models for sustainable innovation: State of-the-art and steps towards a research agenda. Journal of Cleaner Production, 45(Avail), 9-19.

Chesbrough, H., Lettl, C., \& Ritter, T. (2018). Value creation and value capture in open innovation. Journal of Product Innovation Management, 35(6), 930-938.

Colombo, M. G., von Krogh, G., Rossi-Lamastra, C., \& Stephan, P. E. (2017). Organizing for radical innovation: Exploring novel insights. Journal of Product Innovation Management, 34(4), 394-405.

Czakon, W., \& Kawa, A. (2018). Network myopia: An empirical study of network perception. Industrial Marketing Management, 73, 116-124.

Dubois, A., \& Gadde, L. (2002). Systematic combining: An adductive approach to case research. Journal of Business Research, 55(7), 553-560.

Eikhof, D.R., \& Haunschild, A. (2007). For art's sake! Artistic and economic logics in creative production. Journal of Organizational Behavior, 28(5), 523-538. 
Faems, D., de Visser, M., Andries, P., \& van Looy, B. (2010). Technology alliance portfolios and financial performance: Value-enhancing and cost-increasing effects of open innovation. Journal of Product Innovation Management, 27(6), 785-796.

Figge, F., \& Hahn, T. (2012). Is green and profitable sustainable? Assessing the trade-off between economic and environmental aspects. International Journal of Production Economics, 140(1), 92-102.

Frishammar, J., \& Hörte, S. Å. (2005). Managing external information in manufacturing firms: The impact on innovation performance. Journal of Product Innovation Management, 22(3), 251-266.

Gligor, D. (2018). Performance implications of the fit between suppliers' flexibility and their customers' expected flexibility: A dyadic examination. Journal of Operations Management, 58-59 (March), 73-85.

Håkansson, H., \& Ford, D. (2002). How should companies interact in business networks? Journal of Business Research, 55 (2), 133-139.

Laursen, K., \& Salter, A. J. (2014). The paradox of openness: Appropriability, external search and collaboration. Research Policy, 43(5), 867-878.

Lin, S. (2018). The structural characteristics of innovation ecosystem: A fashion case. European Journal of Innovation, 21(4), 620-635.

Linderman, K., \& Chandrasekaran, A. (2010). The scholarly exchange of knowledge in operations management. Journal of Operations Management, 28(4), 357-366.

Malhotra, M.K., \& Mackelprang, A.W. (2012). Are internal manufacturing and external supply chain flexibilities complementary capabilities? Journal of Operations Management, 30(3), 180-200.

Mandal, S. (2015). Supply and demand effects on supply chain flexibility: An empirical exploration. Knowledge Process Management, 22(3), 206-219.

Meredith, J. R., \& Pilkington, A. (2018). Assessing the exchange of knowledge between operations management and other fields: Some challenges and opportunities. Journal of Operations Management, 60(May), 47-53.

Ozer, M., \& Zhang, G. (2018). The roles of knowledge providers, knowledge recipients, and knowledge usage in bridging structural holes. Journal of Product Innovation Management (in press), 1-17.

Qi Dong, J., McCarthy, K. J., \& Schoenmakers, W. W. (2017). How central is too central? Organizing interorganizational collaboration networks for breakthrough innovation. Journal of Product Innovation Management 34(4), 526-542.

Spender, J., Corvello, V., Grimaldi, M., \& Rippa, P. (2017). Startups and open innovation: A review of the literature. European Journal of Innovation Management, 20(1), 4-30.

Stake, R. E. (1995). The art of case study research. CA: SAGE Publications, Thousand Oaks.

Stojcic, N., Hashi, I., \& Olric, E. (2018). Creativity, innovation effectiveness and productive efficiency in the UK. European Journal of Innovation, 21(4), 564-580.

West, L., \& Bogers, M. (2014). Leveraging external sources of innovation: A review of research on open innovation. Journal of Product Innovation Management, 31(4), 814-831.

Yin, R. (2003). Applications of case study research. (2nd ed.). CA: SAGE Publications, Thousand Oaks.

Yusuf, J. (2009). From creativity to innovation. Technology in Society, 31(1), 1-8. 